\title{
Free and cued selective reminding test predicts progression to Alzheimer's disease in people with mild cognitive impairment
}

\author{
Giulia Grande $^{1,2}$ (D) Nicola Vanacore ${ }^{3}$. Davide L Vetrano ${ }^{1,4,5} \cdot$ Ilaria Cova $^{2} \cdot$ Debora Rizzuto $^{1} \cdot$ Flavia Mayer $^{3}$. \\ Laura Maggiore $^{2} \cdot$ Roberta Ghiretti $^{2} \cdot$ Valentina Cucumo $^{2} \cdot$ Claudio Mariani $^{2} \cdot$ Stefano F Cappa $^{6,7} \cdot$ Simone Pomati $^{2}$
}

Received: 21 March 2018 / Accepted: 18 July 2018 / Published online: 26 July 2018

(C) The Author(s) 2018

\begin{abstract}
Introduction To assess the diagnostic accuracy of the free and cued selective reminding test (FCSRT) for the development of Alzheimer's disease (AD) in people with mild cognitive impairment (MCI).

Methods We enrolled 187 consecutive MCI outpatients from a memory clinic that were evaluated at baseline and every 6 to 12 months through an extensive clinical and neuropsychological protocol. For each test, measures of diagnostic accuracy were obtained. To improve the overall specificity of the neuropsychological battery, we also used the diagnostic tests in parallel combination. The association between FCSRT indexes and AD was tested through proportional hazard regression models with other dementia subtypes as competing event. Laplace regression was used to model time-to-AD diagnosis as a function of FCSRT indexes. Results The area under the curve of the FCSRT indexes ranged from 0.69 (95\% CI: $0.62-0.76$ ) to 0.76 (95\% CI: 0.70-0.82). The specificity peaked up to $100 \%$ when we combined the category fluency test with the delayed total recall index of the FCSRT. Participants who tested positive at the FCSRT, as compared with those with negative tests, presented a twofold to fivefold higher risk of developing $\mathrm{AD}$ (median follow-up time 2.5 years; $p<0.001)$ and were diagnosed with $\mathrm{AD} 2-3$ years earlier $(p<0.001$ ). Discussion The FCSRT assessment suite shows the best predictive performance in detecting AD in people with MCI. These findings might help to reliably and timely identify people at higher risk of AD that is crucial both for properly selecting participants to clinical trials and to fine tune an effective and patient-centered care.
\end{abstract}

Keywords Alzheimer's disease $\cdot$ Free and cued selective reminding test $\cdot$ Mild cognitive impairment $\cdot$ Longitudinal study

Electronic supplementary material The online version of this article (https://doi.org/10.1007/s10072-018-3507-y) contains supplementary material, which is available to authorized users.

Giulia Grande

giulia.grande@ki.se

1 Aging Research Center, Department of Neurobiology, Care Sciences, and Society (NVS), Karolinska Institutet and Stockholm University, Tomtebodavägen 18A, 17165 Solna, Sweden

2 Center for Research and Treatment on Cognitive Dysfunctions, "Luigi Sacco" University Hospital, Milan, Italy

3 National Centre of Epidemiology, National Institute of Health, Rome, Italy

4 Department of Geriatrics, Catholic University of Rome, Milan, Italy

5 Centro di Medicina dell'Invecchiamento, Fondazione Policlinico A. Gemelli, Rome, Italy

6 NeTS Center, Istituto Universitario di Studi Superiori, Pavia, Italy

7 IRCCS S. Giovanni di Dio Fatebenefratelli, Brescia, Italy

\section{Introduction}

The World Alzheimer Report estimated that approximately 131 million people are expected to live with dementia by 2050, worldwide [1,2]. In spite of such burdensome epidemics, so far, no effective curative or disease-modifying treatment has been identified. Noticeably, the inclusion in randomized controlled trials of persons with an overt evidence of cognitive impairment may have limited the efficacy of the tested treatments [3]. Hence, increasing efforts have been paid toward the identification of putative modifiable risk factors and in favor of an earlier detection of AD [4-6]. Recently, research focused on the development of tools able to increase the specificity of diagnosis of prodromal $\mathrm{AD}[7,8]$. In this regard, neuropsychological tests have been deemed as pivotal both in clinical and research contexts, as they are easy to administer, inexpensive, and non-invasive [9].

The distinctive feature of typical amnestic AD is the presence of a paradigmatic and specific episodic memory 
involvement, characterized by a diminished free recall ability, which is only marginally improved by cueing [10]. The free and cued selective reminding test (FCSRT) has been used with the aim of maximizing the differentiation between the genuine hippocampal deficit of AD and age-associated memory dysfunction, due to impaired attention, inefficient information processing, and ineffective retrieval $[11,12]$. The International Working Group (IWG) recommends the use of the FCSRT as a reliable tool for the assessment of this specific cognitive deficit [7].

The FCSRT has been extensively studied during the past years, with promising results [13-15]. Previous studies have demonstrated that the FCSRT is an appropriate tool to detect $\mathrm{AD}$ at early stages and predict future cases of dementia in cognitively intact or mildly impaired people $[11,15]$. However, some results go in the opposite direction; namely, a handful of studies failed in demonstrating a superiority of the FCSRT with respect to other routine memory tests $[16,17]$. These findings suggest that ensuring for a controlled encoding and testing for cued recall does not imply a better predictive power than free recall tests [16]. Those studies were conducted mainly in research settings, with limited comparisons between FCSRT and other neuropsychological tests and without providing estimations of the timing from the test administration to $\mathrm{AD}$ diagnosis.

In the present study, we aim to investigate the diagnostic accuracy for the diagnosis of AD of FCSRT in people with mild cognitive impairment referring to a memory clinic.

\section{Materials and methods}

\section{Study population}

We consecutively recruited outpatients from the Center for Research and Treatment of Cognitive Dysfunctions, Luigi Sacco Hospital, University of Milan, from May 2009 to January 2016. Participants were evaluated at baseline and reevaluated every 6 to 12 months as part of the clinical routine $[18,19]$. During each visit, demographic, functional, and clinical information was gathered through a comprehensive assessment. Follow-up ended at the diagnosis of AD, dementia, death, or at the end of the cohort surveillance (July 2016), whichever came first.

The ethic committee of the "Luigi Sacco" Hospital approved the study protocol. Informed written consent from all subjects was obtained.

Participants were included if they met the diagnostic criteria of MCI [20], based on an extensive neuropsychological battery. MCI was operationalized as follows: (1) subjective cognitive complaint as reported by the subject and/or corroborated by an informant, (2) objective cognitive impairment, according to age-specific and education-specific norms
[21], on at least one task of the neuropsychological battery, (3) essentially preserved daily functioning defined as no impairment in basic activities of daily living (ADL) [22] and unimpaired or minimally impaired (i.e., impairment in one IADL) complex instrumental activities of daily living (IADL) [23], and (4) the absence of dementia defined according to DSM-IV criteria (Diagnostic and Statistical Manual of Mental Disorders). Based on the impaired domains on the neuropsychological battery, MCI participants were then classified as "non-amnestic single domain MCI" (impairment in one cognitive domain other than memory), "amnestic MCI," (impairment only in memory tasks), or "multiple domain MCI" (impairment in at least two cognitive domains). Multiple domain MCI included both people with multiple domain amnestic and non-amnestic MCI.

Exclusion criteria were (1) severe psychiatric disorders (e.g., major depression, bipolar disorders, psychotic symptoms), (2) structural brain alterations (e.g., mass lesions and hydrocephalus) or organic illnesses affecting the brain, (3) history of severe traumatic brain injury, (4) major systemic illnesses or medical complications, with uncontrolled organ failure, (5) sensory disorders that could prevent the correct administration of the neuropsychological battery (i.e., blindness or deafness), and (6) history of substance or alcohol abuse.

Comorbidity burden was assessed using the Cumulative Illness Rating Scale (CIRS) comorbidity index [24]. Depression was assessed using the 30 -item version of the Geriatric Depression Scale (considering $\geq 10$ as the presence of clinically relevant depressive symptoms) [25].

Subjects were also offered APOE genotyping, and the results from the tests of those who accepted (130 subjects; 70\% of the whole sample) were included in a supplementary analysis. As compared to those who accepted the APOE genotyping, those who refused did not have any statistically significant difference in terms of demographics, global cognitive performance as assessed with the MMSE, and chronic comorbidities as assessed with the CIRS.

\section{Neuropsychological battery}

Participants were assessed by trained neuropsychologists (RG, VC) following a standardized procedure. The neuropsychological battery assessed the whole cognitive spectrum including declarative long-term memory (story recall, the Rey Auditory Verbal Learning Test-RAVLT, and the Rey complex figure recall), language abilities (letter and category fluency), visuospatial and visuo-perceptual abilities (the Rey complex figure copy test and the clock-drawing test), and executive functions and attention (the Raven Colored Progressive Matrices 47 tests, the Trail Making Test parts A and B, the frontal assessment battery, the Stroop Color-Word Test). The battery was administered in a standardized 
sequence, alternating verbal and non-verbal tests, with the aim of avoiding the risk of proactive and retroactive interference in memory tests. All test scores, when appropriate, were adjusted for age and educational level according to available normative data [21, 26, 27]. The Clinical Dementia Rating [28] (CDR) was used as a measure of global cognition.

\section{FCSRT procedure}

All participants were administered with the Italian version of the FCSRT, whose normative data and cutoff for each score have been previously published $[12,29]$. Briefly, the test has two different parts, the study and the memory ones. In the study phase, which ensures encoding, the examiner asks for pointing and naming 12 stimuli presented in three different cards. The card is then removed and immediate recall was examined. When the item is not recalled, the examiner shows the card again to test immediate recall again. The memory part consists of three recall trials, with a non-semantic interference task before (counting backwards for $20 \mathrm{~s}$ ). First, participants need to recall as many items as possible in $2 \mathrm{~min}$. Then, those non-retrieved items are recalled through one specific semantic cue for each stimulus. If the participant fails to retrieve the item with the category cue, the examiner verbally reminds the item. After $30 \mathrm{~min}$, the same procedure is used to test delayed recall. Each trial is scored based on the number of recalled items and five scores are derived: (1) immediate free recall (IFR), (2) immediate total recall (ITR), (3) delayed free recall (DFR), (4) delayed total recall (DTR), (5) index of sensitivity of cueing (ISC).

\section{Dementia and AD diagnosis}

In the present study, we considered as outcome the diagnosis of dementia in keeping with the DSM-IV criteria [30], which requires the evidence of cognitive decline on the neuropsychological test battery and impairment on social or occupational functioning. The diagnosis was established by a consensus panel of a neurologist (SP, LM, IC, or GG) and a neuropsychologist (RG or VC). Furthermore, dementia subtypes were defined as follows: AD according to NIA-AA criteria [31], Lewy body dementia according to McKeith criteria [32], frontotemporal dementia according to Rascovsky criteria [33], and vascular dementia according to NINDS-AIREN criteria [34].

The results of the present study were reported in keeping with the STROBE recommendations (Appendix, Table S1).

\section{Statistical analyses}

Participants' characteristics are reported as means and standard deviation (SD) or frequencies (\%). The two-tail Pearson's $\chi^{2}$ test and the analysis of the variance (ANOVA) were used to compare sample characteristics according to incident dementia. Multiple-comparison post-hoc analyses were also performed.

Diagnostic accuracy measures (i.e., sensitivity, specificity, positive predictive values, negative predictive values, positive likelihood ratios, negative likelihood ratios, and area under the curve) and their $95 \%$ confidence intervals (95\% CI) were obtained for each cognitive test, using the clinical diagnosis of $\mathrm{AD}$ as a reference standard. To assess the strength and the consistency of the results, sensitivity analyses were also performed: (1) considering as a reference standard the clinical diagnosis of dementia (all types) according to DSM-IV, (2) restricting the analyses only to participants with amnestic impairments, (3) including only participants with a MMSE score $\geq 24$, as a measure of severity of cognitive impairment [35].

In order to achieve a better diagnostic accuracy, we combined in parallel the pair of tests presenting the highest specificity and sensitivity. To increase sensitivity, we considered the test combination as positive when either one or both tests (i.e., those with the highest sensitivity) resulted positive. To increase specificity, we considered the test combination as positive when both tests (i.e., those with the highest specificity) resulted positive [36].

The association between FCSRT and the occurrence of AD, with the development of other types of dementia as competing event, was tested through proportional hazard regression models. Adjusted sub-distribution hazard ratios (sHRs) and 95\% CI were obtained for each FCSRT index. Time to event was calculated from the time of enrolment in the study to any of the censoring events reported above. To limit the possibility of reverse causation, we repeated the analyses investigating the same associations considering only those participants who had an observation time of at least 24 months.

Finally, we used the Laplace regression to model the timeto-AD diagnosis as a function of FCSRT indexes. During a mean follow-up of 2 years, approximately $50 \%$ of participants in our cohort developed $\mathrm{AD}$; we therefore chose to examine the median time-to-AD diagnosis. We estimated differences in the time by which the first $50 \%$ of the population developed $\mathrm{AD}$ according to FCSRT indexes [37].

All analyses were performed using Stata version 14 (Stata Corp, Texas, USA), with an $\alpha$ level of $p<0.05$.

\section{Results}

During the mean follow-up period of $2.5 \pm 1.3$ years (interquartile range, IQR: $1.3-3.5$ years), within the 187 participants (mean age at baseline 76 years; $56 \%$ women), 87 (46\%) developed dementia; among them, 73 (84\%) were of AD type. Sample characteristics at baseline according to the development of dementia (of any types and of AD type) are shown in Table 1. In multiple-comparison post-hoc 
Table 1 Baseline characteristics of the whole mild cognitive impairment (MCI) sample and by outcome at follow-up

\begin{tabular}{lllll}
\hline & $\begin{array}{l}\text { Total MCI population } \\
N=187\end{array}$ & $\begin{array}{l}\text { Non-converters at follow-up } \\
N=100\end{array}$ & $\begin{array}{l}\text { AD at follow-up } \\
N=73\end{array}$ & $\begin{array}{l}\text { Non-AD dementia at follow-up } \\
N=14\end{array}$ \\
\hline Age, mean \pm SD & $75.5 \pm 6.8$ & $74.3 \pm 7.3$ & $76.4 \pm 6.1$ & $78.8 \pm 4.6$ \\
Female, $N(\%)$ & $104(56)$ & $48(48)$ & $49(67)$ & $7(50)$ \\
Education, mean $\pm \mathrm{SD}$ & $7.6 \pm 3.7$ & $7.4 \pm 3.6$ & $8.0 \pm 3.7$ & $7.6 \pm 3.9$ \\
MCI subtypes & & & & 0.064 \\
Single domain, $N(\%)$ & $42(23)$ & $28(38)$ & $12(16)$ & $2(14)$ \\
Amnestic, $N(\%)$ & $51(27)$ & $38(38)$ & $10(14)$ & $3(22)$ \\
Multiple domain, $N(\%)$ & $94(50)$ & $34(34)$ & $51(70)$ & $9(64)$ \\
MMSE score, mean $\pm \mathrm{SD}, N(\%)$ & $25.6 \pm 2.4$ & $26.5 \pm 2.0$ & $24.4 \pm 2.6$ & $25.4 \pm 1.8$ \\
CIRS, mean scores $\pm \mathrm{SD}$ & $0.48 \pm 0.28$ & $0.52 \pm 0.28$ & $0.39 \pm 0.21$ & $0.68 \pm 0.40$ \\
APOE, $N(\%)$, any $\varepsilon 4^{\mathrm{b}}$ allele & $41(32)$ & $15(22)$ & $23(43)$ & $3(38)$ \\
\hline
\end{tabular}

Figures reported in the table are numbers $(\%)$ unless otherwise specified

Abbreviations: $S D$, standard deviation; $M M S E$, mini-mental state examination; $C I R S$, Cumulative Illness Rating Scale; $M C I$, mild cognitive impairment; $A D$, Alzheimer's disease; $A P O E$, apolipoprotein E genotype

${ }^{*} p$ value was obtained through $\chi^{2}$ tests for categorical and ANOVA tests for continuous variables

${ }^{a}$ Intended as stable MCI or participants who reverted to a normal state of cognition ( 9 participants)

${ }^{\mathrm{b}}$ On a sample of 130 participants

corrections, those who developed $\mathrm{AD}$ were more likely to be female, to have lower MMSE and CIRS scores than those non-converters ( $p<0.05$ for all comparisons). Those who developed dementia at follow-up (irrespective of the type) were more likely to have a multi-domain MCI than those nonconverters ( $p<0.05$ for all comparisons). No statistically significant differences in the post-hoc analyses arose for what concern age and education in the other groups.

Table 2 shows the diagnostic accuracy measures of the entire neuropsychological battery. The five indexes of the FCSRT had a sensitivity that ranged from 56 (DTR index) to $81 \%$ (DFR sub-item) and a specificity that ranged from 67 (IFR index) up to $83 \%$ (DFR index). Within the five indexes of the FCSRT, the DFR had the best AUC $(0.76 ; 95 \%$ CI: $0.70-0.82)$. All the sensitivity analyses led to similar results (Appendix, Table S2).

When combining the category fluency test $(92.0 ; 95 \% \mathrm{CI}$ : 85.4-96.3) in parallel combination with the DTR index of the FCSRT $(83.3 ; 95 \%$ CI: 75.2-89.7), the overall specificity peaked up to $100 \%$. The overall sensitivity of the delayed recall of Rey Auditory Verbal Learning Test $(75.4 ; 95 \%$ CI: 63.5-84.9) with the DFR index of the FCSRT $(80.8 ; 95 \%$ CI: 69.9-89.1) in parallel combination was $89.9 \%$.

As depicted in Fig. 1, MCI participants with a score below the cutoff in the FCSRT indexes presented a two-to-five times increased risk of incident $\mathrm{AD}$, as compared to those with FCSRT scores above the threshold. More specifically, those with a score below cutoff in the DFR had a more than six times higher risk (sHR: 6.2; 95\% CI: 3.4-11.3) of developing $\mathrm{AD}$ at follow-up compared to those with a normal score and considering the development of other dementia types as a competing event. In the fully adjusted model, we obtained similar, although slightly attenuated, results.

Similar results were also obtained when: (1) repeating the analyses considering only those MCI participants who had at least 1-year follow-up and (2) considering APOE genotype in the fully adjusted model (data not shown).

Figure 2 depicts the differences in the time-to-AD diagnosis as a function of the FCSRT indexes. Participants scoring below threshold in the DFR had a diagnosis of AD approximately 3 years before (median difference: -3.0 years, 95\% CI: $-2.0,-4.0)$ in comparison to those with normal scores in the same index. Participants with a score below cutoff in the IFR, ITR, DTR, and ISC had respectively $2.2(95 \% \mathrm{CI}:-3.6$, -0.7 ), 2.3 (95\% CI: $-3.6,-0.9), 1.7$ (95\% CI: $-3.2,-0.2$ ), and 1.7 (95\% CI: $-3.5,-0.2)$ years before $\mathrm{AD}$ diagnosis as compared to those with a normal score in the same index.

\section{Discussion}

According to our results, as compared to an extensive neuropsychological battery, the FCSRT assessment suite shows the best predictive performance for the development of $\mathrm{AD}$ in people with MCI. Noticeably, a higher specificity was achieved by combining the scores of category fluency test with the DTR index in parallel combination. In addition, participants who tested positive at the FCSRT presented a twofold to fivefold higher risk of developing $\mathrm{AD}$ as compared with those who tested negative. Noteworthy, persons with MCI who tested positive at the FCSRT at baseline were diagnosed with AD 2-3 years earlier than those testing negative. 


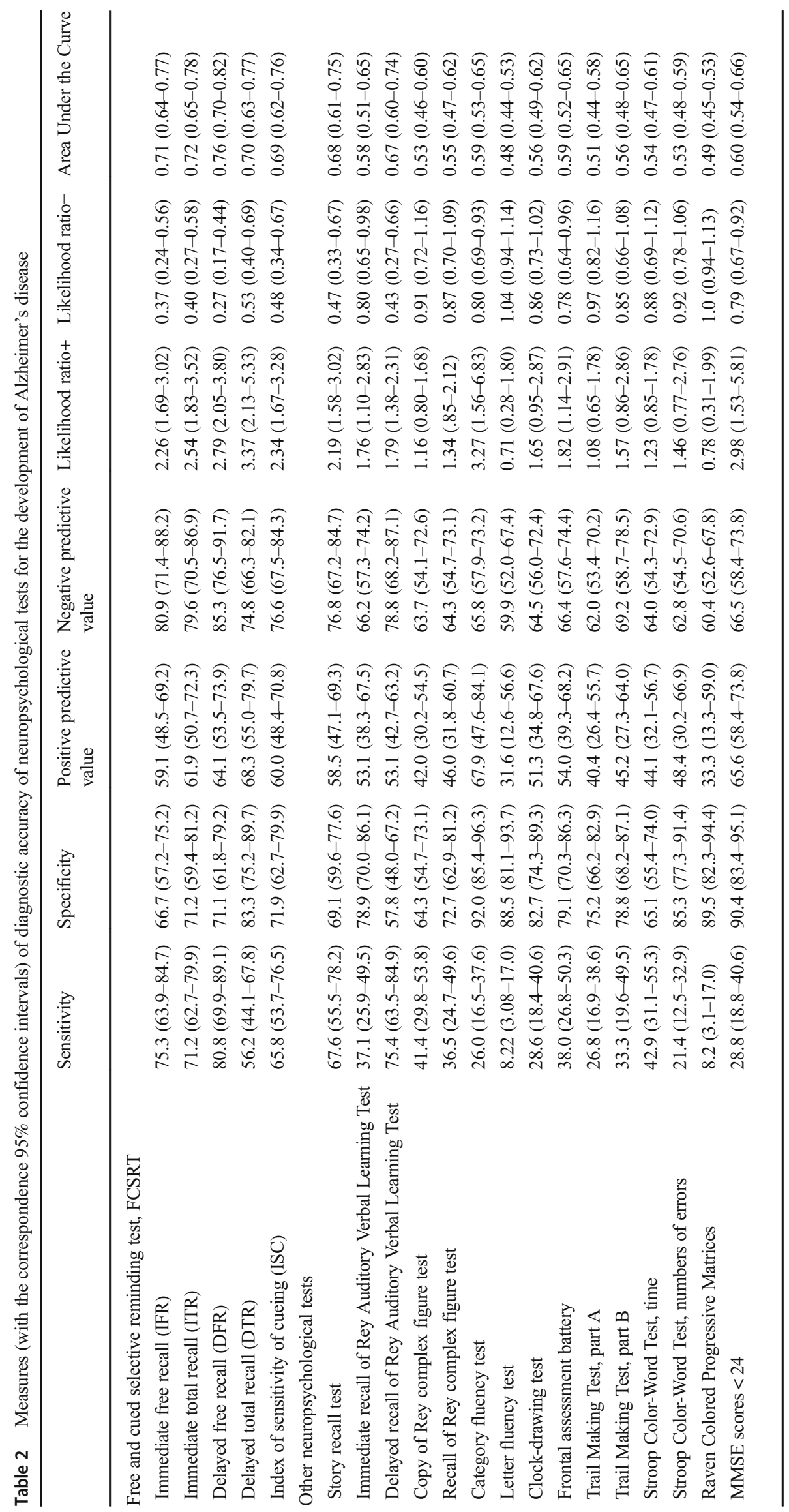




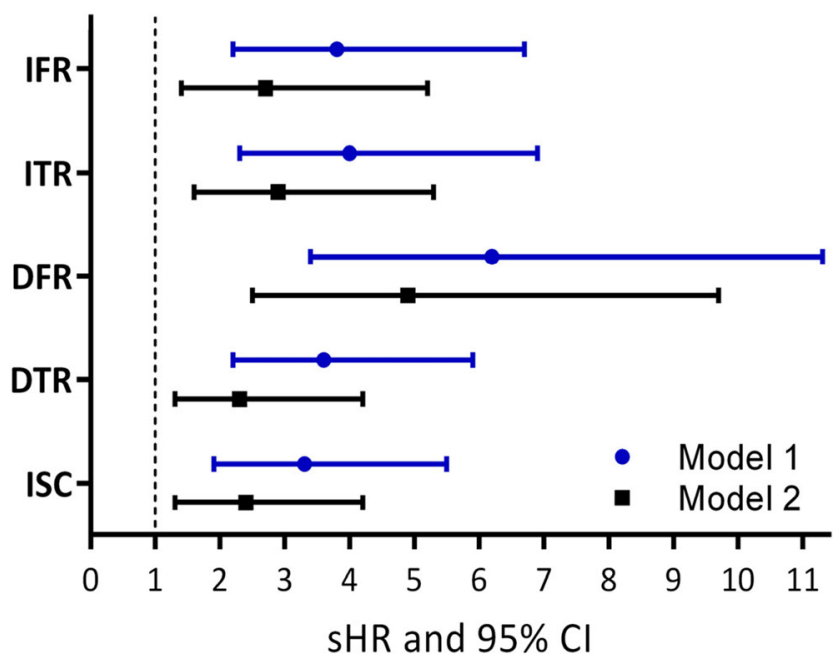

Fig. 1 Association between free and cued selective reminding test (FCSRT) indexes and incident Alzheimer's disease. For each test, the group negative to the test was considered as the reference group. The estimations refer to separate models (one for each FCSRT index). Model 1: basic adjustment for age, sex, and education. Model 2: adjustment for age, sex, education, MCI subtypes, MMSE score, CIRS score

The present findings must be considered in the context of an extensive literature that looked at the role of memory tests as predictors of cognitive decline in the older population. The free and cued selective reminding procedure aims at maximizing the differentiation between the genuine encoding and storage deficits that characterize $\mathrm{AD}$ and the age-associated memory dysfunction, secondary to impaired attention, inefficient

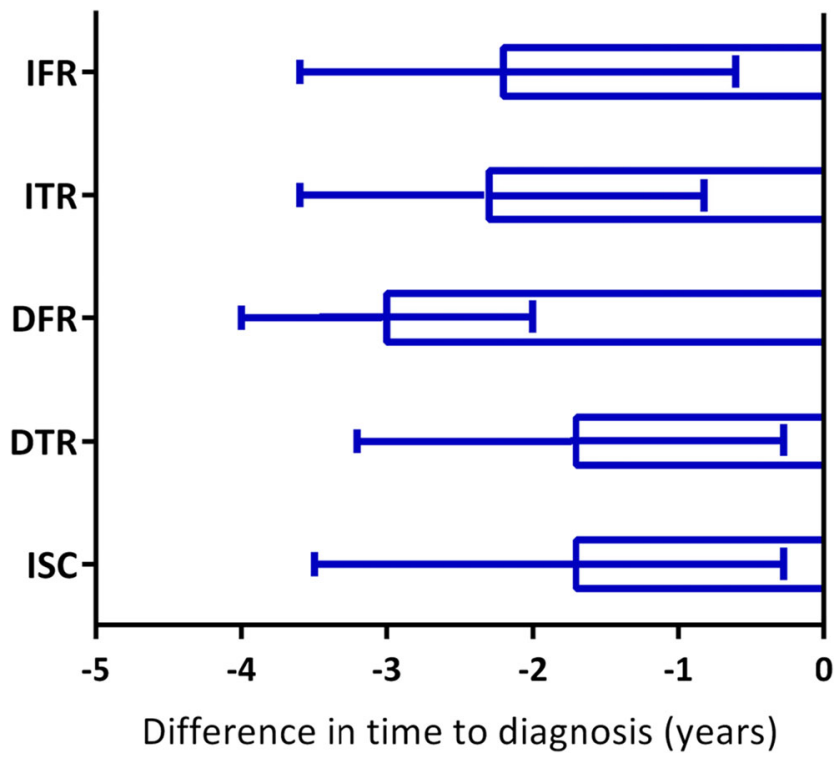

Fig. 2 Difference in time to Alzheimer's disease diagnosis (years) according to participants positive and negative at the FCSRT. For each test, the group negative to the test was considered as the reference group. Model adjusted for age, sex, education, MCI subtypes, MMSE score, CIRS. Abbreviations: IFR, immediate free recall; ITR, immediate total recall; DFR, delayed free recall; DTR, delayed total recall; ISC, index of sensitivity of cueing information processing, and ineffective retrieval [38, 39]. Accordingly, the FCSRT has been consistently considered an appropriate tool to detect AD both in population and clinical-based settings [40, 41] and to distinguish AD from frontotemporal dementia in people with severe cognitive impairment $[13,42]$. In the present study, we confirm the specificity of the FCSRT for the first time through analyses that took into consideration other dementia subtypes as a competing event for incident AD.

In line with a growing body of literature investigating the FCSRT in at risk populations [14, 15, 43, 44], our results further support the crucial role of this test in the assessment of cognitive function in persons with MCI. Notably, we report for the first time the differences in time-to-AD diagnosis as a function of FCSRT scores, showing that persons with MCI who tested positive at the FCSRT are diagnosed with AD 2 3 years before than those testing negative. This finding expands the prior knowledge, empowering the FCSRT assessment of clinical and epidemiological value.

The study by Sarazin and colleagues [15], the first study conducted on people with MCI, suggested the immediate total recall as the best predictor for progression to dementia. The higher predictive value of this score compared to the free recall indicates that the "insensitivity" to cueing might be relevant in the identification of a hippocampal memory deficit, namely the pure memory disorder due to defective storage of information, rather than to poor encoding or retrieval performance. By controlling both for encoding and retrieval with the same semantic cues, the FCSRT can isolate storage deficits linked to an early involvement of hippocampal structures typical of $\mathrm{AD}$, differentiating the memory impairment due to attentional problems and strategic retrieval processes.

Several similar longitudinal studies $[43,44]$ conducted on people with MCI led to comparable results. Lemos and colleagues, in line with our findings, showed a higher risk of developing $\mathrm{AD}$ in amnestic persons with $\mathrm{MCI}$ and positive at the FCSRT, with the total recall score being superior to the logical memory test in predicting such progression [14]. Likewise, the free recall and total recall were slightly better than the CERAD word list in another study, which also suggested an increased predictive value of the combined score [45]. In the present study, among the five indexes of the FCSRT, the ISC presented the poorest predictive power. This result can be surprising, given the theoretical background of the FCSRT and is in contrast with previous studies, which described the ISC as a valid measure in differentiating subtypes of MCI [46]. However, other studies did not confirm such results, particularly in the identification of people who will subsequently develop dementia, with other measures outperforming [16]. Our findings are in line with previous studies, which show the early and reliable deficit in people with MCI and in the older patients who will develop dementia. The use of composite scores may increase the diagnostic 
reliability in dementia prediction. However, the composite scores as substitutes of pure scores (i.e., free and total recall), even if theoretically more appropriate, may lead to a deflation of the global effect, because of the failure of several parameters employed to build the indexes themselves.

To summarize, there is ample evidence supporting the value of the FCSRT to predict progression toward dementia, in particular at risk populations. Our study provides additional valuable information from a monocentric clinical setting with an extended follow-up. This can be considered as a representative sample for a specialized, hospital-based memory clinic. Moreover, our study allows a direct comparison between the FCSRT scores and other memory tests widely used in similar settings (logical memory, word list learning, complex figure recall), and supports the value of combined measures [47]. It is worth mentioning that the version of the FCSRT used for this study was similar in format to the original picture version [39], but used only 12 , rather than 16 stimuli. This allows shortening the testing time, without any loss of predictive value.

Our findings need to be interpreted in the context of the strengths and limitations of the methodology of our study. Major strengths are the large MCI sample - both clinically and psychometrically defined - in a longitudinal study design, and the use of strong outcomes as the clinical diagnosis of $\mathrm{AD}$ and dementia. Moreover, to the best of our knowledge, this is the first study assessing the predictive performance of FCSRT considering as competing risk the development of dementia of other subtypes, and reporting the differences in time-to-AD diagnosis as a function of FCSRT scores. Some limitations should be acknowledged. First, we had a mean observation period of 2.5 years, so it is, in this context, difficult to fully rule out the presence of a reverse causation. Individuals performing worse in the FCSRT scores may have been in a pre-dementia phase. To partially overcome this issue, we conducted a sensitivity analysis considering only those participants with a longer ( $>2$ years) follow-up, and the results were consistent, even though with less power. Second, we considered a sample of MCI people referring to a memory clinic, with a high incident rate of dementia/AD, and this might limit the generalizability of our results. Third, although many covariates have been taken into account in the adjusted analyses, incomplete control of confounding and the effect of unknown confounders may still be present.

In light of the ongoing efforts paid to the development of anti-dementia medications, the identification of people at higher risk of developing AD remains a clinical priority. In this context, the use of cognitive and memory tests to detect mild AD may be effective, and the FCSRT appears to be consistently reliable. Given its characteristics of being also non-invasive and easy to administer, it can be used to assess and recognize impairment in memory of hippocampal type. From a research point of view, this might allow identifying a more homogeneous population for the ongoing clinical trials.
From a clinical standpoint, our results might help physicians in focusing on those MCI people referring to a memory clinic that will benefit from more frequent and regular follow-up, tailoring appropriate treatments and preventive strategies.

Acknowledgments We thank the "Associazione per la Ricerca sulle Demenze" onlus for making this study possible.

We are grateful to Mrs Marica Forcella for the valuable help and assistance in the data collection.

We thank all patients and caregivers for participating in the study.

The authors wish to express their gratitude to Francesca Clerici, for her inspiring insights in the conception of the study.

Author contributions GG, SP, NV, SFC, and CM contributed to the conception and design of the study. LM, RG, VC, IC, and GG collected the data for the study. GG, DLV, FM, and DR did the statistical analyses. All authors contributed to interpretation of the results. GG and DLV drafted the first version of the manuscript. All the authors critically revised the manuscript for important intellectual content. All the authors made a significant contribution to the research and the development of the manuscript and approved the final version.

\section{Compliance with ethical standards}

The ethic committee of the "Luigi Sacco" Hospital approved the study protocol.

Conflict of interest The authors declare that they have no conflict of interest.

Open Access This article is distributed under the terms of the Creative Commons Attribution 4.0 International License (http:// creativecommons.org/licenses/by/4.0/), which permits unrestricted use, distribution, and reproduction in any medium, provided you give appropriate credit to the original author(s) and the source, provide a link to the Creative Commons license, and indicate if changes were made.

\section{References}

1. Alzheimer Disease International, The global impact of dementia. An analysis of prevalence, incidence, costs and trends, 2015

2. Cova I, Markova A, Campini I, Grande G, Mariani C, Pomati S (2017) Worldwide trends in the prevalence of dementia. J Neurol Sci 379:259-260

3. The Lancet, N (2017) WHO has a dementia plan, now we need action. Lancet Neurol 16(8):571

4. Fratiglioni L, Qiu C (2011) Prevention of cognitive decline in ageing: dementia as the target, delayed onset as the goal. Lancet Neurol 10(9):778-779

5. Livingston G, Sommerlad A, Orgeta V, Costafreda SG, Huntley J, Ames D, Ballard C, Banerjee S, Burns A, Cohen-Mansfield J, Cooper C, Fox N, Gitlin LN, Howard R, Kales HC, Larson EB, Ritchie K, Rockwood K, Sampson EL, Samus Q, Schneider LS, Selbæk G, Teri L, Mukadam N (2017) Dementia prevention, intervention, and care. Lancet 390:2673-2734

6. Kivipelto M, Mangialasche F, Ngandu T (2017) Can lifestyle changes prevent cognitive impairment? Lancet Neurol 16(5): 338-339

7. Dubois B, Feldman HH, Jacova C, Hampel H, Molinuevo JL, Blennow K, DeKosky ST, Gauthier S, Selkoe D, Bateman R, Cappa S, Crutch S, Engelborghs S, Frisoni GB, Fox NC, Galasko 
D, Habert MO, Jicha GA, Nordberg A, Pasquier F, Rabinovici G, Robert P, Rowe C, Salloway S, Sarazin M, Epelbaum S, de Souza LC, Vellas B, Visser PJ, Schneider L, Stern Y, Scheltens P, Cummings JL (2014) Advancing research diagnostic criteria for Alzheimer's disease: the IWG-2 criteria. Lancet Neurol 13(6): 614-629

8. Frisoni GB, Boccardi M, Barkhof F, Blennow K, Cappa S, Chiotis K, Démonet JF, Garibotto V, Giannakopoulos P, Gietl A, Hansson O, Herholz K, Jack CR Jr, Nobili F, Nordberg A, Snyder HM, ten Kate M, Varrone A, Albanese E, Becker S, Bossuyt P, Carrillo MC, Cerami C, Dubois B, Gallo V, Giacobini E, Gold G, Hurst S, Lönneborg A, Lovblad KO, Mattsson N, Molinuevo JL, Monsch AU, Mosimann U, Padovani A, Picco A, Porteri C, Ratib O, SaintAubert L, Scerri C, Scheltens P, Schott JM, Sonni I, Teipel S, Vineis P, Visser PJ, Yasui Y, Winblad B (2017) Strategic roadmap for an early diagnosis of Alzheimer's disease based on biomarkers. Lancet Neurol 16(8):661-676

9. Chapman RM, Mapstone M, Porsteinsson AP, Gardner MN, McCrary JW, DeGrush E, Reilly LA, Sandoval TC, Guillily MD (2010) Diagnosis of Alzheimer's disease using neuropsychological testing improved by multivariate analyses. J Clin Exp Neuropsychol 32(8):793-808

10. Markowitsch HJ, Staniloiu A (2012) Amnesic disorders. Lancet 380(9851):1429-1440

11. Auriacombe S, Helmer C, Amieva H, Berr C, Dubois B, Dartigues JF (2010) Validity of the free and cued selective reminding test in predicting dementia: the 3C study. Neurology 74(22):1760-1767

12. Clerici F, Ghiretti R, di Pucchio A, Pomati S, Cucumo V, Marcone A, Vanacore N, Mariani C, Cappa SF (2017) Construct validity of the free and cued selective reminding test in older adults with memory complaints. J Neuropsychol 11(2):238-251

13. Lemos R, Duro D, Simoes MR, Santana I (2014) The free and cued selective reminding test distinguishes frontotemporal dementia from Alzheimer's disease. Arch Clin Neuropsychol 29(7):670-679

14. Lemos R, Marôco J, Simões MR, Santiago B, Tomás J, Santana I (2017) The free and cued selective reminding test for predicting progression to Alzheimer's disease in patients with mild cognitive impairment: a prospective longitudinal study. J Neuropsychol 11(1):40-55

15. Sarazin M, Berr C, de Rotrou J, Fabrigoule C, Pasquier F, Legrain S, Michel B, Puel M, Volteau M, Touchon J, Verny M, Dubois B (2007) Amnestic syndrome of the medial temporal type identifies prodromal AD: a longitudinal study. Neurology 69(19):1859-1867

16. Gainotti G, Quaranta D, Vita MG, Marra C (2014) Neuropsychological predictors of conversion from mild cognitive impairment to Alzheimer's disease. J Alzheimers Dis 38(3):481-495

17. Artero S, Tierney MC, Touchon J, Ritchie K (2003) Prediction of transition from cognitive impairment to senile dementia: a prospective, longitudinal study. Acta Psychiatr Scand 107(5):390-393

18. Cova I, Pomati S, Maggiore L, Forcella M, Cucumo V, Ghiretti R, Grande G, Muzio F, Mariani C (2017) Nutritional status and body composition by bioelectrical impedance vector analysis: a cross sectional study in mild cognitive impairment and Alzheimer's disease. PLoS One 12(2):e0171331

19. Grande G, Vetrano DL, Cova I, Pomati S, Mattavelli D, Maggiore L, Cucumo V, Ghiretti R, Vanacore N, Mariani C, Rizzuto D (2018) Living alone and dementia incidence: a clinical-based study in people with mild cognitive impairment. J Geriatr Psychiatry Neurol 31(3):107-113

20. Winblad B, Palmer K, Kivipelto M, Jelic V, Fratiglioni L, Wahlund LO, Nordberg A, Backman L, Albert M, Almkvist O, Arai H, Basun H, Blennow K, de Leon M, DeCarli C, Erkinjuntti T, Giacobini E, Graff C, Hardy J, Jack C, Jorm A, Ritchie K, van Duijn C, Visser P, Petersen RC (2004) Mild cognitive impairment-beyond controversies, towards a consensus: report of the International Working Group on mild cognitive impairment. J Intern Med 256(3):240-246

21. Capitani E, Laiacona M (1997) Composite neuropsychological batteries and demographic correction: standardization based on equivalent scores, with a review of published data. The Italian Group for the Neuropsychological Study of Ageing. J Clin Exp Neuropsychol 19(6):795-809

22. Katz $\mathrm{S}$ et al (1963) Studies of illness in the aged. The Index of Adl: $A$ Standardized Measure of Biological and Psychosocial Function. JAMA 185:914-919

23. Lawton MP, Brody EM (1969) Assessment of older people: selfmaintaining and instrumental activities of daily living. Gerontologist 9(3):179-186

24. Linn BS, Linn MW, Gurel L (1968) Cumulative Illness Rating Scale. J Am Geriatr Soc 16(5):622-626

25. Yesavage JA, Brink TL, Rose TL, Lum O, Huang V, Adey M, Leirer VO (1982) Development and validation of a geriatric depression screening scale: a preliminary report. J Psychiatr Res 17(1):37-49

26. Magni E, Binetti G, Bianchetti A, Rozzini R, Trabucchi M (1996) Mini-mental state examination: a normative study in Italian elderly population. Eur J Neurol 3(3):198-202

27. Mitchell AJ (2009) A meta-analysis of the accuracy of the minimental state examination in the detection of dementia and mild cognitive impairment. J Psychiatr Res 43(4):411-431

28. Hughes CP, Berg L, Danziger WL, Coben LA, Martin RL (1982) A new clinical scale for the staging of dementia. Br J Psychiatry 140: 566-572

29. Frasson P, Ghiretti R, Catricalà E, Pomati S, Marcone A, Parisi L, Rossini PM, Cappa SF, Mariani C, Vanacore N, Clerici F (2011) Free and cued selective reminding test: an Italian normative study. Neurol Sci 32(6):1057-1062

30. Diagnostic, A.P.A.D.-I., and statistical manual on mental disorders, and D. Washington.

31. McKhann GM, Knopman DS, Chertkow H, Hyman BT, Jack CR Jr, Kawas CH, Klunk WE, Koroshetz WJ, Manly JJ, Mayeux R, Mohs RC, Morris JC, Rossor MN, Scheltens P, Carrillo MC, Thies B, Weintraub S, Phelps CH (2011) The diagnosis of dementia due to Alzheimer's disease: recommendations from the National Institute on Aging-Alzheimer's Association workgroups on diagnostic guidelines for Alzheimer's disease. Alzheimers Dement 7(3): 263-269

32. McKeith IG, Dickson DW, Lowe J, Emre M, O'Brien JT, Feldman H, Cummings J, Duda JE, Lippa C, Perry EK, Aarsland D, Arai H, Ballard CG, Boeve B, Burn DJ, Costa D, del Ser T, Dubois B, Galasko D, Gauthier S, Goetz CG, Gomez-Tortosa E, Halliday G, Hansen LA, Hardy J, Iwatsubo T, Kalaria RN, Kaufer D, Kenny RA, Korczyn A, Kosaka K, Lee VMY, Lees A, Litvan I, Londos E, Lopez OL, Minoshima S, Mizuno Y, Molina JA, MukaetovaLadinska EB, Pasquier F, Perry RH, Schulz JB, Trojanowski JQ, Yamada M, for the Consortium on DLB (2005) Diagnosis and management of dementia with Lewy bodies: third report of the DLB Consortium. Neurology 65(12):1863-1872

33. Rascovsky K, Hodges JR, Knopman D, Mendez MF, Kramer JH, Neuhaus J, van Swieten JC, Seelaar H, Dopper EGP, Onyike CU, Hillis AE, Josephs KA, Boeve BF, Kertesz A, Seeley WW, Rankin KP, Johnson JK, Gorno-Tempini ML, Rosen H, Prioleau-Latham CE, Lee A, Kipps CM, Lillo P, Piguet O, Rohrer JD, Rossor MN, Warren JD, Fox NC, Galasko D, Salmon DP, Black SE, Mesulam M, Weintraub S, Dickerson BC, Diehl-Schmid J, Pasquier F, Deramecourt V, Lebert F, Pijnenburg Y, Chow TW, Manes F, Grafman J, Cappa SF, Freedman M, Grossman M, Miller BL (2011) Sensitivity of revised diagnostic criteria for the behavioural variant of frontotemporal dementia. Brain 134(Pt 9):2456-2477

34. Sachdev P, Kalaria R, O'Brien J, Skoog I, Alladi S, Black SE, Blacker D, Blazer DG, Chen C, Chui H, Ganguli M, Jellinger K, 
Jeste DV, Pasquier F, Paulsen J, Prins N, Rockwood K, Roman G, Scheltens P, Internationlal Society for Vascular Behavioral and Cognitive Disorders (2014) Diagnostic criteria for vascular cognitive disorders: a VASCOG statement. Alzheimer Dis Assoc Disord 28(3):206-218

35. Creavin ST et al (2016) Mini-mental state examination (MMSE) for the detection of dementia in clinically unevaluated people aged 65 and over in community and primary care populations. Cochrane Database Syst Rev 1:CD011145

36. Weinstein S, Obuchowski NA, Lieber ML (2005) Clinical evaluation of diagnostic tests. AJR Am J Roentgenol 184(1):14-19

37. Orsini N., B., M. ,(2011) Laplace regression. Stata Journal

38. Buschke H (1984) Cued recall in amnesia. J Clin Neuropsychol 6(4):433-440

39. Grober E, Buschke H, Crystal H, Bang S, Dresner R (1988) Screening for dementia by memory testing. Neurology $38(6)$ : 900-903

40. Grober E, Kawas C (1997) Learning and retention in preclinical and early Alzheimer's disease. Psychol Aging 12(1):183-188

41. Grober E, Lipton RB, Hall C, Crystal H (2000) Memory impairment on free and cued selective reminding predicts dementia. Neurology 54(4):827-832

42. Grober E, Hall C, Sanders AE, Lipton RB (2008) Free and cued selective reminding distinguishes Alzheimer's disease from vascular dementia. J Am Geriatr Soc 56(5):944-946
43. Mura T, Proust-Lima C, Jacqmin-Gadda H, Akbaraly TN, Touchon J, Dubois B, Berr C (2014) Measuring cognitive change in subjects with prodromal Alzheimer's disease. J Neurol Neurosurg Psychiatry 85(4):363-370

44. Di Stefano F et al (2015) Prediction of Alzheimer's disease dementia: data from the GuidAge prevention trial. J Alzheimers Dis 48(3): 793-804

45. Sala I, Illán-Gala I, Alcolea D, Sánchez-Saudinós MB, Salgado SA, Morenas-Rodríguez E, Subirana A, Videla L, Clarimón J, Carmona-Iragui M, Ribosa-Nogué R, Blesa R, Fortea J, Lleó A (2017) Diagnostic and prognostic value of the combination of two measures of verbal memory in mild cognitive impairment due to Alzheimer's disease. J Alzheimers Dis 58(3):909-918

46. Perri R, Monaco M, Fadda L, Serra L, Marra C, Caltagirone C, Bruni AC, Curcio S, Bozzali M, Carlesimo GA (2015) Influence of controlled encoding and retrieval facilitation on memory performance in patients with different profiles of mild cognitive impairment. J Neurol 262(4):938-948

47. Coley N, Gallini A, Ousset PJ, Vellas B, Andrieu S (2016) Evaluating the clinical relevance of a cognitive composite outcome measure: an analysis of 1414 participants from the 5-year GuidAge Alzheimer's prevention trial. Alzheimers Dement 12(12):1216-1225 